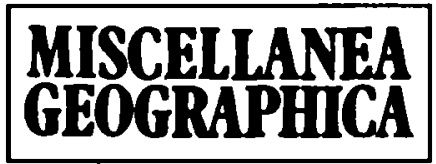

WARSZAWA 1992 Vol. 5

Urszula Kossowska-Cezak

\title{
THE THERMAL AND PRECIPITATION CONDITIONS OF THE SUMMER MONTHS AND SEASONS IN WARSAW
}

The air temperature and the amount of precipitation during one day depend on a synoptic situation; thus they are interrelated. However, the diversity of processes giving rise to the occurrence of precipitation causes that the mean air temperature may be accompanied by both: high amount of precipitation and its complete absence. Thus the given monthly temperature may be accompanied by a different amount of monthly precipitation. The aim of this paper is to examine the relationship between the mean monthly temperature and the monthly sum of precipitation in the summer months in Warsaw, as well as to define conditions that favour the occurrence of the extremum monthly values of these elements of climate. As a material for this paper data were used from the years 1871-1970 of the Astronomical Observatory station in the city centre and from the years 19511990 of the Okęcie station in the suburbs. The months from June to August and the entire seasons were analyzed separately.

To distinguish groups of months and average seasons, cold and warm as well as dry and rainy, two methods were applied: the three-class equal-probability division and the values of deviation from the many years' average exceeding 1 or 2 standard deviations. The merit of the first method is an equal (practically approximate) number of the classes distinguished, which makes it easier to compare the results; an advantage of the other are the objective statistical criteria permitting to distinguish anomalous nonths and seasons both in terms of temperature and precipitation.

In conformity with the first method, all months and seasons within the 100 years' period and separately within the 40 years' period were divided into three equal groups according to the growing values of temperature: cold, normal and warm, and then, according to the growing amount of precipitation, into dry, normal and rainy. As a result, a division into 9 groups (categories) was obtained, of which the values underwent test $\chi^{2}$. The consistent result obtained shows that the warm months and seasons are usually dry, and the cold ones are rainy. This relationship was more conspicuous in the 100 years' period than in the 40 years' one, and in the 100 years' period mostly in July (Table 1) and in the whole season (Table 2). The probability that such an outcome in July is accidental is 
barely 0.001 , in summer 0.02 , and in June and August around 0.05 ; in the 40 years in the whole season around 0.05 .

The number of months of various thermal and precipitation categories, July 1871-1970

\begin{tabular}{|l|c|c|c|c|}
\hline P & cold & normal & warm & $\Sigma$ \\
\hline dry & 5 & 10 & 18 & 33 \\
\hline normal & 10 & 15 & 9 & 34 \\
\hline rainy & 19 & 8 & 6 & 33 \\
\hline$\Sigma$ & 34 & 33 & 33 & 100 \\
\hline
\end{tabular}

$\chi^{2}=18.44$
The number of months of the summer seasons of various thermal and precipitation categories, 1871-1970

\begin{tabular}{|l|r|r|r|c|}
\hline t & cold & normal & warm & $\Sigma$ \\
\hline dry & 6 & 12 & 15 & 33 \\
\hline normal & 10 & 14 & 10 & 34 \\
\hline rainy & 17 & 11 & 5 & 33 \\
\hline$\Sigma$ & 33 & 37 & 30 & 100 \\
\hline
\end{tabular}

$\chi^{2}=11.10$

The structure of the particular classes of temperature and precipitation was examined. It turned out that the normal seasons most often consisted of 3 months of various categories, and normal seasons without normal months are more frequent than those composed of 3 normal months. In the cold and warm, dry and rainy seasons 2 such months and one normal occur most frequently, though a month of the opposite category is also possible. Similar results were obtained on the basis of both series (100 and 40 years) and in relation to the thermal and precipitation conditions, with two differences: (1) seasons consisting of months of 3 various categories are more frequent in case of precipitation (one-fourth of all seasons) than temperature (one-sixth of seasons), and such a combination usually makes up a normal season in respect of precipitation but only in half of cases a normal season in respect of temperature; (2) cool and warm seasons consisting of 3 such months happen twice as often as dry and rainy seasons comprising the same 3 months. These differences indicate a greater homogeneity of the thermal conditions than precipitation conditions during a season. No single summer season was found which would be normal with regard to temperature and precipitation and which would be composed of 3 months of this kind. This shows a great variability of thermal and precipitation conditions during a season and conventionality of the term 'normal season'.

The average air temperature and the amount of precipitation in each of 9 categories of summer seasons (Table 3 ) were calculated. It turned out that a mean value in the given category of temperature is very similar in all precipitation categories, though within the 100 years' period in the rainy seasons it ranged from 0.1 to $0.3^{\circ} \mathrm{C}$ lower than in the dry ones. But the unexpected differences appeared in the mean amounts of precipitation: they were definitely lower (about 30 per cent) in the dry and cool months than in the dry and warm months. This result was obtained within the 100 years' as well as in the 40 years' series. In the 
group of the rainy months, precipitation in cool and normal months was greater (about 10 per cent) than in the warm ones. A quite different result was obtained within the 40 years' series; only one warm and rainy season took place but the precipitation in this season was highest in the 40 -year period.

Table 3

Average temperature and amount of precipitation in the summer seasons of various thermal and precipitation categories, 1971-1970

\begin{tabular}{|l|c|r|r|l|c|c|c|}
\hline \multicolumn{5}{|c|}{ Temperature $\left[{ }^{\circ} \mathrm{C}\right]$} & \multicolumn{4}{c|}{ Precipitation [mm] } \\
\hline seasons & cold & normal & warm & seasons & cold & normal & warm \\
\hline dry & 17.0 & 18.1 & 19.0 & dry & 125 & 158 & 178 \\
\hline normal & 17.1 & 18.0 & 18.9 & normal & 214 & 213 & 212 \\
\hline rainy & 16.9 & 17.9 & 18.7 & rainy & 296 & 304 & 275 \\
\hline
\end{tabular}

In conformity with the assumption of the three-class equal-probability division among the normal months and seasons are counted only one-third of all cases, the remaining two-thirds being considered as deviated from the standard. In order to strengthen the criterion, as the normal months and seasons were taken those in which the average monthly temperature and the amount of precipitation differ from the respective value of many-years' average no more than one standard deviation $(\sigma)$. The months and seasons were distinguished as:

$\begin{array}{llll}\text { very cold } & \mathrm{t}<\overline{\mathrm{t}}-2 \sigma & \text { very dry } & \mathrm{p}<\overline{\mathrm{p}}-2 \sigma \\ \text { cold } & \overline{\mathrm{t}}-2 \sigma \leq \mathrm{t}<\overline{\mathrm{t}}-\sigma & \text { dry } & \overline{\mathrm{p}}-2 \sigma \leq \mathrm{p}<\overline{\mathrm{p}}-\sigma \\ \text { normal } & \overline{\mathrm{t}}-\sigma \leq \mathrm{t} \leq \overline{\mathrm{t}}+\sigma & \text { normal } & \overline{\mathrm{p}}-\sigma \leq \mathrm{p} \leq \overline{\mathrm{p}}+\sigma \\ \text { warm } & \overline{\mathrm{t}}+\sigma<\mathrm{t} \leq \overline{\mathrm{t}}+2 \sigma & \text { rainy } & \overline{\mathrm{p}}+\sigma<\mathrm{p} \leq \overline{\mathrm{p}}+2 \sigma \\ \text { very warm } & \overline{\mathrm{t}}+2 \sigma<\mathrm{t} & \text { very rainy } & \overline{\mathrm{p}}+2 \sigma<\mathrm{p}\end{array}$

Very dry months and seasons have not occurred. As it was expected, the most numerous category turned out to be a category of months and seasons being normal simultaneously in respect of temperature and precipitation, comprising nearly half of cases, as well as considerably frequent months and seasons with the opposite sign of deviation of temperature and precipitation rather than with the same sign (Table 4). July distinguished itself more frequently as a cold and very cold month (normal in respect of precipitation and rainy), and August as warm and very warm (normal and dry). This regularity has manifested itself in the two periods alike.

In order to find out causes of the occurrence of months and seasons which had been extreme in respect of temperature and precipitation the types of the atmospheric circulation were investigated in these periods. On the average, over the Polish territory the most frequent is the type of anticyclonic Western circulation (18 per cent of days) and North-Eastern (16 per cent), as well as cyclonic NorthWestern (16 per cent), and North-Eastern and Eastern (12 per cent) can be observed (Osuchowska-Klein 1978). The analysis revealed that cold months and 
The number of normal and anomalous summer seasons, 1871-1970

\begin{tabular}{|l|c|r|r|r|r|}
\hline \multicolumn{1}{|c|}{$\mathbf{t}$} & $\begin{array}{c}\text { very } \\
\text { cold }\end{array}$ & \multicolumn{1}{|c|}{ cold } & normal & warm & $\begin{array}{c}\text { very } \\
\text { warm }\end{array}$ \\
\hline dry & 1 & 1 & 12 & 2 & 1 \\
\hline normal & $\cdot$ & 5 & 46 & 13 &. \\
\hline rainy &. & 3 & 12 &. &. \\
\hline very rainy &. & 2 & 2 &. &. \\
\hline
\end{tabular}

seasons are characterized by the increased precipitation and the two Northern cyclonic types, particularly of the North-Western one; in the coolest summer of $1923\left(t=15.8^{\circ} \mathrm{C}\right)$ the share of the circulation of this type was twice as large than the average; in the coolest July in 1902 it reached 62 per cent, and in the coolest June in 1923 it amounted to 57 per cent. The warm months and seasons were characterized by an increased share of usually rare types of anticyclonic circulations from the Southern sector (8 per cent on the average); in June and July rather from South-Western sector and in August from the South-Eastern one. In the warmest summer of $1939\left(t=20.6^{\circ} \mathrm{C}\right)$ the share of the two types was 29 per cent; in the warmest June in 1917 the share of the South-Western type was 23 per cent; in the warmest July in 1959 it was 16 per cent; and in the warmest August in 1939 the share of the South-Eastern type was 52 per cent. A frequency of the two most frequent summer types of circulation, that is anticyclonic Western and North-Eastern was extremely varied in the cold seasons (months) and in the warm ones. If the Western cyclonic type associated with the Azorian high pressure wedge over Western Europe occurred alternately with the cyclonic types from the Western sector, the summer (month) was cool; if with the Southern types - it was warm. The anticyclonic North-Eastern type occurred more often in the warm years than in the cool ones, and in some of them even prevailed, as e.g. in June 1917 (27 per cent), in July 1959 (36 per cent), in August 1939 (32 per cent) (but in the coolest August 1936 - 39 per cent), in the summer of 1939 - 20 per cent. Thus it can be concluded that in the summer an advection of the continental air from the North-East on the peripheries of high pressure with its centre over Scandinavia usually favours an increase in temperature in Poland.

A dependence of the monthly amount of precipitation on the circulation type marks itself very weakly. In the rainy months and seasons cyclonic types are more often to appear, while in the dry ones - anticyclonic, but it is not a rule: in the six most rainy summers $(317-386 \mathrm{~mm})$, a frequency of the cyclonic types was 51-65 per cent, but in the subsequent rainy season $(316 \mathrm{~mm})$ only 36 per cent; in the four driest summers $(92-102 \mathrm{~mm}$ ) a share of the anticyclonic types amounted to 55-64 per cent, but in the subsequent dry season $(105 \mathrm{~mm})$ only 30 per cent. The predominance of the frequency of the days of anticyclonic circulation in the dry seasons (months) is marked, however, more distinctly than the cyclonic one in the rainy seasons. For example, in the most rainy June $(159 \mathrm{~mm}, 1959)$ and the 
driest one $(10 \mathrm{~mm}, 1930)$, the share of the anticyclonic types was the same (70 per cent). In 1959, precipitation occurred mostly on some few days of the Western cyclonic circulation; it was a very intensive precipitation accompanied by storms. Such abundant precipitation of the convectional origin is also feasible on the days of anticyclonic circulation from the Eastern sector. In such a situation, precipitation often occurred in the warm and most rainy summer of the 40year period (1951-1990), that is in 1972.

The analysis of the thermal and precipitation conditions in the summer months and seasons in Warsaw in the years 1971- 1990 has shown that a similar average temperature can be accompanied by various amounts of precipitation, but precipitation in the warmest months and seasons is most often below standard while in the coolest - above it. However, the anomalous months and seasons are rare and are caused by a clear domination of the atmospheric circulation from one sector or from one type of circulation only. The average seasons, both in respect of temperature and precipitation are around 50 per cent but 40 per cent on the average because of one of these elements. However, "average" does not mean equable conditions but an alternate occurrence of positive and negative deviations in the course of temperature and precipitation. This is caused by a continuous changeability of the character of circulation. This variability of the types of weather and of the character of the circulation is the most characteristic feature of climate in Poland.

\section{REFERENCES}

O s u ch ow s ka-Kle in B., 1978, Katalog typow cyrkulacji atmosferycznej (The catalogue of the types of atmospheric circulation), Wyd. Komunikacji i Łączności, Warszawa. 
